https://dx.doi.org/10.4314/ijs.v23i1.12

Ife Journal of Science vol. 23, no. 1 (2021)

\title{
PREVALENCE OF OTITIS MEDIA IN CHILDREN ATTENDING A PRIMARY HEALTH CARE CENTER IN SAMARU, ZARIA, NIGERIA
}

\author{
Atta*, H. I. and Umar, F. F. \\ Department of Microbiology, Ahmadu Bello University, Zaria, Nigeria. \\ *Author for correspondence. E-mail address: hiatta@abu.edu.ng \\ (Received: $23^{\text {rd }}$ June, 2019; Accepted: $30^{\text {th }}$ September, 2019)
}

\section{ABSTRACT}

\begin{abstract}
Otitis media is an inflammatory disease of the mucosal lining of the middle ear. It occurs more frequently in children due to the shorter and more horizontal eustachian tube in their ears. The focus of this study is determining the prevalence of otitis media in children aged 6 months -10 years attending a primary health care facility in Samaru, Zaria, Nigeria. Fifty swabs from ear discharge and imparted wax were obtained from the study subjects regardless of whether they were presenting with symptoms of otitis media or not. Information on certain symptoms, as well as demographic and risk factors was obtained through the use of questionnaires. A prevalence of $54 \%$ of otitis media was obtained in this study. The following bacterial species were isolated: Pseudomonas aeruginosa (25.7\%), Escherichia coli (25.7\%), Klebsiella pneumoniae (14.3\%), Staphylococcus aureus (14.3\%), Proteus mirabilis (8.6\%), Coagulase negative Staphylococci (8.6\%) and Proteus vulgaris (3.7\%). The infection was observed to be higher in children in the age range, six months to two years. Risk factors such as the use of cotton buds in cleaning the ear, posture of the child during breast-feeding and not being exclusively breast-fed were shown to be very prominent among the children studied. Antibiotic susceptibility tests revealed that among the Gram negative bacteria isolated, Psendomonas aeruginosa and Klebsiella pneumoniae were resistant to more than two antibiotics. Coagulase negative Staphylococcus was resistant to all the antibiotics except Ceftriaxone, Streptomycin and Cefuroxime. On the other hand, Staphylococcus aureus was susceptible to all the antibiotics tested with the exception of Cefuroxime, Ceftriaxone and Ampiclox. Therefore, it is recommended that antibiotic susceptibility testing be conducted before treatment of otitis media in children. The importance of exclusive breast-feeding and good personal hygiene should be emphasized to nursing mothers.
\end{abstract}

Key words: Otitis media, Children, Bacteria, Antibiotics, Zaria

\section{INTRODUCTION}

Otitis media is an inflammatory disease of the mucosal lining of the middle ear, which includes a variety of medical conditions with different signs and symptoms (Ogbogu et al., 2013). It occurs in the area between the tympanic membrane and the inner ear (Jido et al., 2014), which includes the middle ear cavity (tympanic cavity), mastoid antrum, mastoid air cells and the eustachian tube (Ilechukwu et al., 2014). The infection associated with otitis media is most commonly caused by the buildup of fluid behind the ear drum as a result of a blockage to the eustachian tube. It occurs when the eustachian tube becomes swollen or blocked and traps fluid in the middle ear. By reflux or aspiration of unwanted secretions from the nasopharynx into the normally sterile middle-ear space, the trapped fluid can become infected, leading to inflammation. The causative organisms may be in the nose, sinus or in the oropharynx and tonsils. Bacterial infections of the middle ear normally originate from the upper respiratory tract. Otitis media has been classified into three main types such as Acute Otitis Media (AOM), Otitis Media with Effusion (OME) and Chronic Otitis Media with Effusion (COME). The four main causes of otitis media are allergy, infection, blockage of the Eustachian tube and nutritional deficiency (Jido et al., 2014).

Etiologic agents for otitis media include viruses and bacteria (Ilechukwu et al., 2014). Predominant bacteria that cause otitis media are: Psendomonas sp., Staphylococcus aureus, Protens mirabilis Klebsiella pneumoniae, Streptococcus pneumoniae, Escherichia coli etc. The notable viruses include: Rhinovirus, Adenovirus, Parainfluenza, Coronavirus and respiratory syncytial virus (Ilechukwu et al., 2014). Risk factors associated with otitis media include: children between the ages of 6-36 months, using a pacifier; children attending daycare being bottlefed instead of being breast-fed; exposure to cigarette smoke; infected or large adenoids; exposure to high level of air pollution; experiencing changes in altitude and climate; cold, flu and sinus infection. 
A number of measures decrease the risk of otitis media including pneumococcal and influenza vaccine, exclusive breast-feeding for the first six months of life, avoiding tobacco smoke. There is some evidence that breast-feeding for the first year of life is associated with a reduction in the number and duration of otitis media infections (Dewey et al., 1995). Pacifier use, on the other hand, has been associated with more frequent acute otitis media. Evidence does not support zinc supplementation as an effort to reduce otitis media rates except maybe in those with severe malnutrition such as marasmus (Gulani et al., 2014). Treatment include elimination of predisposing factor and use of suitable antimicrobial agents- the antibacterials like Tetracycline, Penicillin, Erythromycin, Chloramphenicol, Gentamicin, Ciprofloxacin, Norfloxacillin, Cotrimoxazole, Ceftriaxone, Ampicillin and Amoxicillin (Muluye, 2013), and antifungals like Clotrimazole, Miconazole, Econazole, Nystatin, Tolnaftate and Potassium Sorbate (Khan et al., 2013).

Otitis media is a persistent, insidious and potentially dangerous disease because of its various complications such as loss of hearing, delayed speech and language in children (Moses, 2010). It is still a significant health problem especially in developing countries where not many institutions have facilities for a standard microbiology laboratory. Thus, the aim of this study was to determine the prevalence of otitis media in children attending a Primary Health Care Center in Samaru, Zaria, Northern Nigeria.

\section{MATERIALS AND METHODS}

\section{Ethical Approval:}

Permission for this study was obtained from the authorities in the Health Center, and the objectives of the study clearly and simply explained to all individuals participating in the study, verbal informed consent was obtained.

\section{Study Population and Duration of Study:}

The study populations were children aged 6 months-10 years attending Primary Health Care Center, Samaru, Zaria, between April - May 2016.

\section{Sample Size:}

A total of fifty samples were obtained from the children.

\section{Data Collection:}

Questionnaires were used to obtain data based on the study variables containing certain demographic and risk factors associated with otitis media.

\section{Sample Collection:}

Ear swab samples were collected using a sterile swab stick. The samples were then transported immediately to the Microbiology Laboratory in the Department of Microbiology, Ahmadu Bello University, Zaria, for isolation and identification of bacteria.

\section{Isolation of Bacteria from Ear Swabs:}

The collected samples were inoculated on mannitol salt agar and MacConkey agar by first making a pool with the cotton swab then streaking with a sterile wire loop to reduce concentration and to obtain discrete colonies, and then sub cultured on mannitol salt agar, MacConkey agar and Cetrimide agar to ascertain the purity of the isolates. The plates were incubated aerobically at $37^{\circ} \mathrm{C}$ for $24 \mathrm{~h}$.

Plates were examined at the end of incubation period for lactose fermentation on MacConkey agar and mannitol fermentation on mannitol salt agar and the morphological characteristics (size, shape, colour and pigment production) were recorded.

\section{Biochemical Characterization of the Isolates:}

Gram's staining was carried out to confirm the Gram's reaction of the isolates. And then subsequently, biochemical characterization was carried out. Colonies showing $\alpha$-hemolysis on blood agar and yellow colonies on mannitol salt agar were subjected to catalase and coagulase test. On MacConkey agar, colonies that showed lactose fermentation were subjected to indole, methyl red, Voges-Proskauer, citrate utilization tests; while colonies that showed non-lactose fermentation were subjected to indole, methyl red, VogesPoskauer, citrate utilization, gelatin hydrolysis, motility and urease tests for further confirmation of the isolates. 
Antimicrobial Susceptibility Testing Using Disk Diffusion Technique (Kirby-Bauer Method) Preparation and Standardization of Inoculum Several colonies of similar appearance of the test organism were emulsified in a small volume of sterile distilled water. The suspension was standardized by comparing the turbidity with that of 0.5 McFarland standard (Cheesbrough, 2006).

A sterile swab stick was dipped into the standardized inoculum and pressed against the container to reduce excess inoculum. The swab stick was used to swab the entire surface of the Muller- Hinton agar plate. The plate was allowed to stand for few minutes, and then a multiple antibiotic disk was placed on the surface of the inoculated plates using a sterile pair of forceps.
The plate was incubated at $37^{\circ} \mathrm{C}$ for $24 \mathrm{~h}$., and the diameter of the zones observed was measured.

\section{RESULTS}

Of the fifty samples analyzed, 27 (54\%) of them yielded bacterial growth, of which $8(16 \%)$ yielded at least two bacterial species while, $19(38 \%)$ yielded a single organism. Twenty three (23) samples showed no growth (Table 1).

From the study, thirty five (35) bacterial species were isolated which include Psendomonas aeruginosa (25.7\%), Escherichia coli $(25.7 \%)$, Klebsiella pneumoniae (14.3\%), Staphylococcus aureus (14.3\%), Coagulase negative Staphylococcus (CoNS) (8.6\%), Proteus mirabilis $(8.6 \%)$ and Proteus vulgaris $(2.9 \%)$ (Table 2).

Table 1: Distribution of Bacterial Genera Isolated from Ear Swab of Children attending Primary Health Center in Samaru, Zaria

\begin{tabular}{ccc}
\hline Type of growth & Number & Percentage \\
\hline Mixed genera & 8 & $16 \%$ \\
Single genus & 19 & $38 \%$ \\
No growth & 23 & $46 \%$ \\
Total & 50 & $100 \%$ \\
\hline
\end{tabular}

Table 2: Occurrence of Bacteria Isolated from Ear Swabs of Children attending Primary Health Center in Samaru, Zaria

\begin{tabular}{cc}
\hline Isolate & No. present $(\%)$ \\
& $\mathrm{N}=35$ \\
\hline Pseudomonas aeruginosa & $9(25.7 \%)$ \\
Escherichia coli & $9(25.7 \%)$ \\
Staphylococcus aureus & $5(14.3 \%)$ \\
Klebsiella pneumoniae & $5(14.3 \%)$ \\
Proteus mirabilis & $3(8.9 \%)$ \\
Coagulase negative Staphylococcus & $3(8.9 \%)$ \\
Proteus vulgaris & $1(2.9 \%)$ \\
\hline
\end{tabular}

The study showed that the highest number of isolates $(44 \%)$ was found in the age group, 6 months -2 years while the age group of $>5$ years had the least (Table 3). In this study, $54 \%$ of the patients were males and $46 \%$ were females.

The data from questionnaire provided information on risk factors and symptoms associated with otitis media. The risk factors include: exclusive breastfeeding, the posture of the child during breastfeeding and cleaning of ear using cotton bud; while the following symptoms were analyzed; catarrh, sore throat, earache, discharge from the ear and use of pacifier (Table 4).

The antibiotic susceptibility tests for both Gram negative and Gram positive bacteria revealed that 
the former were susceptible to Ciprofloxacin, the Gram positive organisms were susceptible to Ofloxacin and Sparfloxacin and were resistant to Ciprofloxacin and resistant to Cefuroxime, Amoxicillin, Augmentin and Streptomycin. While Cotrimoxazole and Erythromycin (Table 5).

Table 3: Occurrence of Bacteria Associated with Otitis Media in Children Based on Age

\begin{tabular}{ccccc}
\hline Age group & Mixed organisms & Single organism & No growth & Total \\
\hline$<6$ months & $1(2 \%)$ & $4(8 \%)$ & $4(8 \%)$ & $9(18 \%)$ \\
6 months -2 & $3(6 \%)$ & $9(18 \%)$ & $10(20 \%)$ & $22(44 \%)$ \\
years & & & & \\
$3-5$ years & $0(0 \%)$ & $3(6 \%)$ & $7(7 \%)$ & $10(20 \%)$ \\
$>5$ years & $4(8 \%)$ & $3(6 \%)$ & $2(4 \%)$ & $9(18 \%)$ \\
Total & $8(16 \%)$ & $19(38 \%)$ & $23(46 \%)$ & $50(100 \%)$ \\
\hline
\end{tabular}

Table 4: Risks Factors of Otitis Media as Observed among the Children

\begin{tabular}{cccccc}
\hline & $\mathrm{A}$ & $\mathrm{B}$ & $\mathrm{C}$ & $\mathrm{D}$ & $\mathrm{E}$ \\
YES & $40 \%$ & $62 \%$ & $86 \%$ & $46 \%$ & $10 \%$ \\
NO & $60 \%$ & $38 \%$ & $14 \%$ & $54 \%$ & $90 \%$ \\
\hline
\end{tabular}

Key:

A: Exclusive breastfeeding

B: Does the child lie on the side during breastfeeding?

C: Cleaning of ear using cotton bud

D: Presence of one or more of these symptoms: catarrh, sore throat, earache or discharge from ear

E: Use of pacifier.

Table 5: Antibiotic Susceptibility Pattern** of Gram Negative Bacteria Isolated from Ear Swabs of Children

\begin{tabular}{|c|c|c|c|c|c|}
\hline Antibiotics & $\begin{array}{l}\text { E. coli } \\
\mathrm{N}=9\end{array}$ & $\begin{array}{l}\text { P. aeruginosa } \\
\mathrm{N}=9\end{array}$ & $\begin{array}{l}\text { K. pneumoniae } \\
\mathrm{N}=5\end{array}$ & $\begin{array}{l}\text { P. mirabilis } \\
\mathrm{N}=3\end{array}$ & $\begin{array}{l}\text { P. vulgaris } \\
\mathrm{N}=1\end{array}$ \\
\hline Amoxacillin $(30 \mu \mathrm{g})$ & $\begin{array}{l}\mathrm{S}(44.4 \%) \mathrm{R} \\
(55.6 \%)\end{array}$ & $\begin{array}{l}\text { S }(22.2 \%) \mathrm{R} \\
(77.8 \%)\end{array}$ & $\begin{array}{l}\text { S (60\%) R } \\
(40 \%)\end{array}$ & $\begin{array}{l}\text { S }(100 \%) \mathrm{R} \\
(0 \%)\end{array}$ & $\begin{array}{l}\text { S }(100 \%) \mathrm{R} \\
(0 \%)\end{array}$ \\
\hline Ciprofloxacin $(10 \mu \mathrm{g})$ & $\begin{array}{l}\text { S }(88.9 \%) \mathrm{R} \\
(11.1 \%)\end{array}$ & $\begin{array}{l}\text { S }(100 \%) \mathrm{R} \\
(0 \%)\end{array}$ & $\begin{array}{l}\text { S }(100 \%) \mathrm{R} \\
(0 \%)\end{array}$ & $\begin{array}{l}\text { S }(100 \%) \mathrm{R} \\
(0 \%)\end{array}$ & $\begin{array}{l}\text { S }(100 \%) \mathrm{R} \\
(0 \%)\end{array}$ \\
\hline $\begin{array}{l}\text { Chloramphenicol } \\
(30 \mu \mathrm{g})\end{array}$ & $\begin{array}{l}\mathrm{S}(66.7 \%) \mathrm{R} \\
(33.3 \%)\end{array}$ & $\begin{array}{l}\mathrm{S}(55.6 \%) \mathrm{R} \\
(44.4 \%)\end{array}$ & $\begin{array}{l}\text { S (60\%) R } \\
(40 \%)\end{array}$ & $\begin{array}{l}\text { S }(100 \%) \mathrm{R} \\
(0 \%)\end{array}$ & $\begin{array}{l}\text { S }(100 \%) \mathrm{R} \\
(0 \%)\end{array}$ \\
\hline Gentamicin $(10 \mu \mathrm{g})$ & $\begin{array}{l}\mathrm{S}(55.6 \%) \mathrm{R} \\
(44.4 \%)\end{array}$ & $\begin{array}{l}\mathrm{S}(33.3 \%) \mathrm{R} \\
(66.7 \%)\end{array}$ & $\begin{array}{l}\mathrm{S}(60 \%) \mathrm{R} \\
(40 \%)\end{array}$ & $\begin{array}{l}\text { S }(100 \%) \mathrm{R} \\
(0 \%)\end{array}$ & $\begin{array}{l}\text { S }(100 \%) \mathrm{R} \\
(0 \%)\end{array}$ \\
\hline Sparfloxacin $(10 \mu \mathrm{g})$ & $\begin{array}{l}\mathrm{S}(66.7 \%) \mathrm{R} \\
(33.3 \%)\end{array}$ & $\begin{array}{l}\mathrm{S}(77.8 \%) \mathrm{R} \\
(22.2 \%)\end{array}$ & $\begin{array}{l}\text { S }(100 \%) \mathrm{R} \\
(0 \%)\end{array}$ & $\begin{array}{l}\text { S }(0 \%) \mathrm{R} \\
(100 \%)\end{array}$ & $\begin{array}{l}\text { S }(100 \%) \mathrm{R} \\
(0 \%)\end{array}$ \\
\hline Cotrimoxazole $(30 \mu \mathrm{g})$ & $\begin{array}{l}\mathrm{S}(66.7 \%) \mathrm{R} \\
(33.3 \%)\end{array}$ & $\begin{array}{l}\mathrm{S}(66.7 \%) \mathrm{R} \\
(33.3 \%)\end{array}$ & $\begin{array}{l}\mathrm{S}(60 \%) \mathrm{R} \\
(40 \%)\end{array}$ & $\begin{array}{l}\mathrm{S}(66.7 \%) \mathrm{R} \\
(33.3 \%)\end{array}$ & $\begin{array}{l}\text { S }(100 \%) \mathrm{R} \\
(0 \%)\end{array}$ \\
\hline Augmentin $(30 \mu \mathrm{g})$ & $\begin{array}{l}\text { S (33.3\%) R } \\
(66.7 \%)\end{array}$ & $\begin{array}{l}\text { S }(33.3 \%) \mathrm{R} \\
(66.7 \%)\end{array}$ & $\begin{array}{l}\mathrm{S}(60 \%) \mathrm{R} \\
(40 \%)\end{array}$ & $\begin{array}{l}\text { S }(100 \%) \mathrm{R} \\
(0 \%)\end{array}$ & $\begin{array}{l}\text { S }(100 \%) \mathrm{R} \\
(0 \%)\end{array}$ \\
\hline Ofloxacin $(10 \mu \mathrm{g})$ & $\begin{array}{l}\text { S }(77.8 \%) \mathrm{R} \\
(22.2 \%)\end{array}$ & $\begin{array}{l}\text { S }(100 \%) \mathrm{R} \\
(0 \%)\end{array}$ & $\begin{array}{l}\text { S }(100 \%) \mathrm{R} \\
(0 \%)\end{array}$ & $\begin{array}{l}\text { S }(100 \%) \mathrm{R} \\
(0 \%)\end{array}$ & $\begin{array}{l}\text { S9100\%) R } \\
(0 \%)\end{array}$ \\
\hline 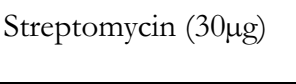 & $\begin{array}{l}\text { S }(33.3 \%) R \\
(66.7 \%)\end{array}$ & $\begin{array}{l}\mathrm{S}(44.4 \%) \mathrm{R} \\
(55.5 \%)\end{array}$ & $\begin{array}{l}\mathrm{S}(40 \%) \mathrm{R} \\
(60 \%)\end{array}$ & $\begin{array}{l}\text { S }(100 \%) \mathrm{R} \\
(0 \%)\end{array}$ & $\begin{array}{l}\text { S }(100 \%) \mathrm{R} \\
(0 \%)\end{array}$ \\
\hline
\end{tabular}

** Clinical and Laboratory Standards Institute (CLSI), 2014 


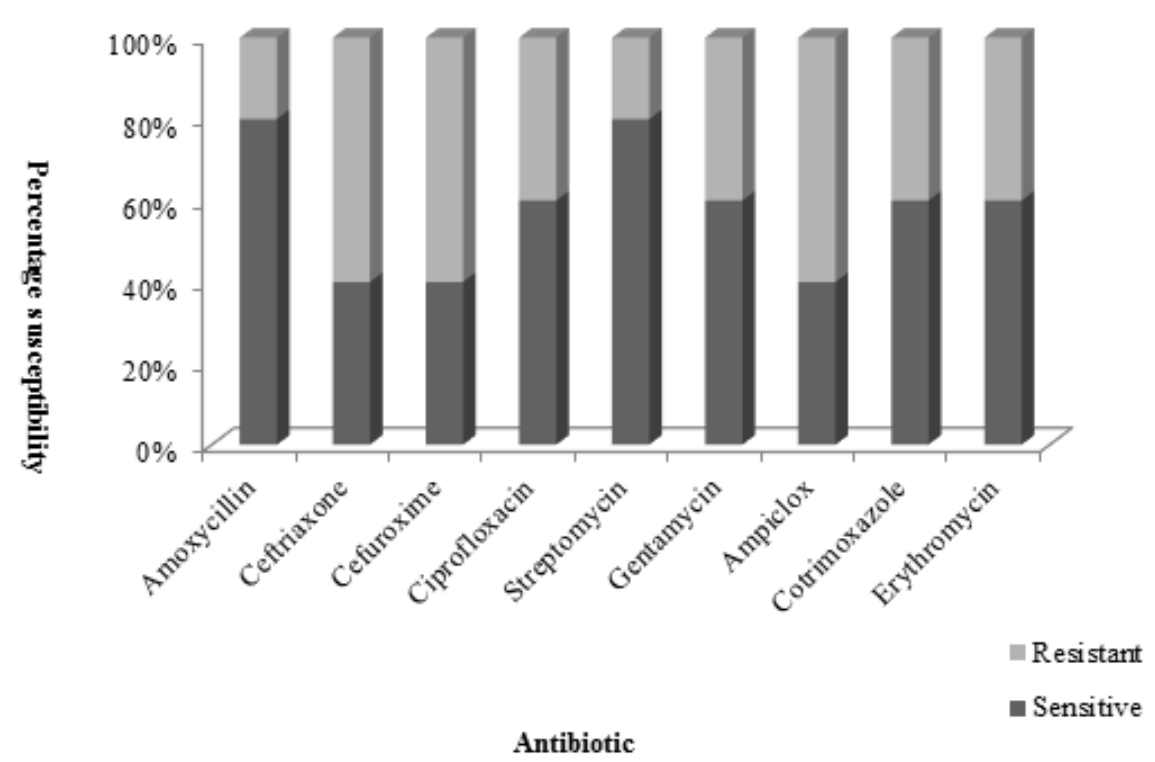

Figure 1: Antibiotic Susceptibility Pattern of Staphylococcus Aureus Isolated from Ear Swabs of Children $(\mathrm{N}=5)$

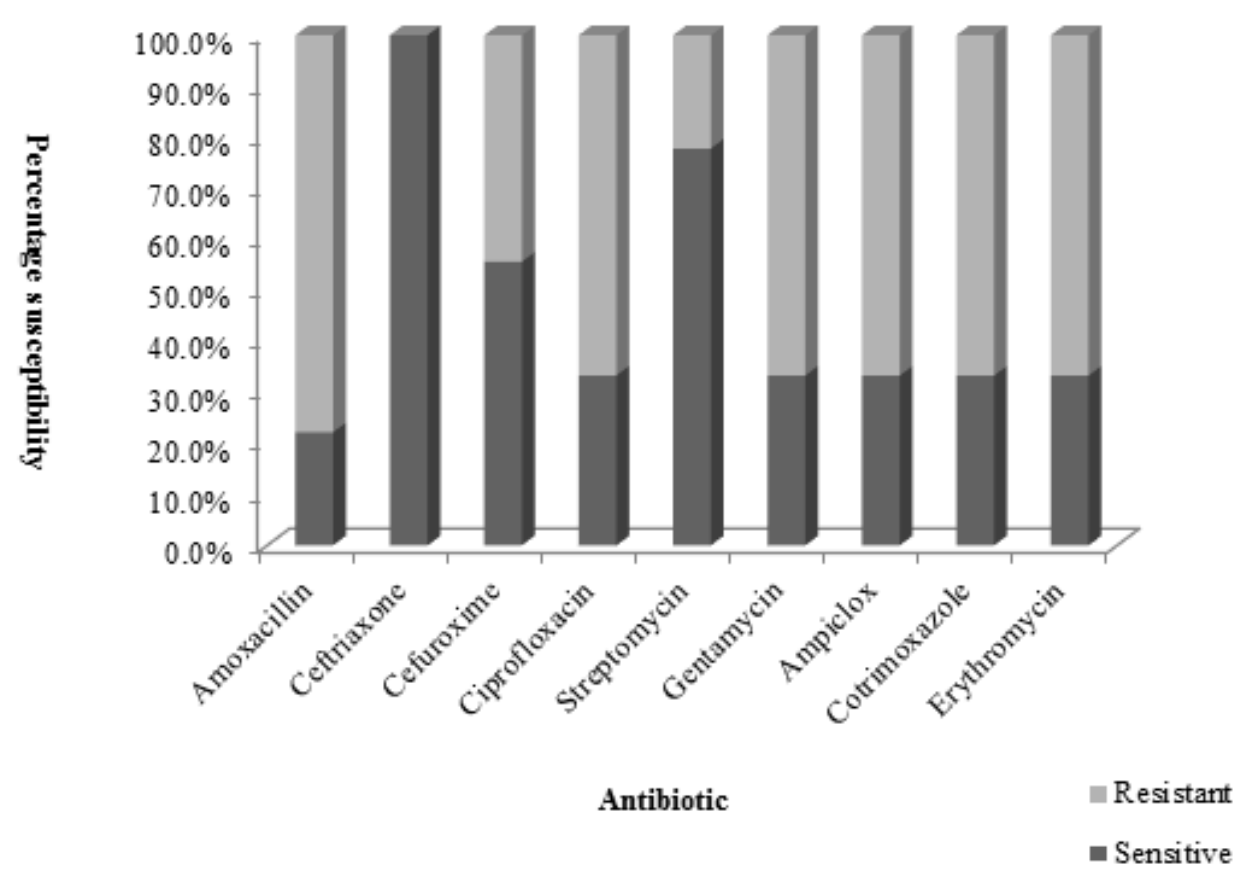

Figure 2: Antibiotic Susceptibility Pattern of Coagulase Negative Staphylococcus Isolated from Ear Swabs of Children $(\mathrm{N}=3)$

\section{DISCUSSION}

The prevalence of otitis media in this study was $54 \%$. This prevalence was higher than previous studies conducted in Nigeria (Amusa et al., 2005; Tikaram et al., 2012). This might be due to a number of possible reasons which include: inaccessibility to health care facility, local customs and beliefs, harmful traditional practices and poor treatment of acute cases by the first contact health personnel. However, the prevalence in this study was lower than that reported by Ogbogu et al. (2013).

Pseudomonas aeruginosa (25.7\%) and Escherichia coli 
$(25.7 \%)$ were the predominant bacteria isolated, which is similar to other studies carried out in Nigeria and Ghana (Nwokoye et al., 2012; AppiahKorang et al., 2014 and Nwogwugwu et al., 2014). It was also partly similar to studies in Ethiopia which had Proteus spp. $(27.5 \%)$ and Staphylococcus aureus $(26.5 \%)$, as the predominant organisms isolated (Muluye et al., 2013). Also a study in Morocco showed that Streptococcus pneumoniae was found to be the most common bacterial pathogen $(40.30 \%)$ (Imane et al., 2014). Pseudomonas aeruginosa is a common environmental organism usually found in warm and moist environments, and is known to colonize the external auditory canal. It is commonly associated with otitis externa and chronic superlative otitis media. Escherichia coli is also an opportunistic pathogen that can cause diseases when it leaves its natural habitat (Price et al., 2017). A significant proportion of the study population $(16 \%)$ was infected by more than one bacterial species; similar situations of mixed bacterial or viral-bacterial infections have been reported by Ogbogu et al. (2013) and Muluye et al. (2013). The negative cultures observed suggest that other etiological agents of infections (virus or fungi) might be implicated in the infection since there was obvious discharge from some of those samples. In such patients, antibiotic therapy may not be beneficial (Nwokoye et al., 2012).

The findings of this study showed that otitis media can affect children in the age range of six months to ten years, with higher prevalence amongst those aged six months to two years. This is similar to the outcome of a study in Nigeria by Ilechukwu et al. (2014) which showed that infants and young children are at highest risk of developing otitis media, with peak prevalence between six and thirty six months of age. Age was considered a risk factor because eustachian tubes of children (less than 5 years of age) are shorter and more horizontally positioned than that of adults. This positioning allows for reflux of commensal organisms from the nasopharynx to the sterile middle ear resulting in congestion of the tube (Nwokoye et al., 2012).

The responses from the questionnaires revealed that three of the risk factors featured in $>50 \%$ of the children. These factors are use of cotton buds $(86 \%)$, lying on the side during breastfeeding
$(62 \%)$, and not exclusively breast-fed (60\%). This is an indication that a good number of the children were predisposed to otitis media. The infection was higher in children that had not experienced exclusive breast-feeding. This was similar to some studies in which exclusive breast-feeding until the age of 4 months and partially thereafter was associated with a significant reduction of respiratory and gastrointestinal morbidity in infants (Monasta et al., 2012). Infants' feeding habits such as lying on the side during breastfeeding increases the risk of otitis media as it can cause reflux of microorganisms from the nasopharnyx to the middle ear. The presence of one or more of the symptoms associated with otitis media in $46 \%$ of the children in this study is evidence that otitis media is likely a common problem among children in the study population and mothers of young children and infants need to be enlightened on ways of preventing this infection.

The antibiotic susceptibility test carried out revealed that most of the Gram negative bacteria were susceptible to Ciprofloxacin (99.6\%), Ofloxacin $(92.6 \%)$ and Sparfloxacin $(81.5 \%)$, and resistant to Amoxacillin, Augmentin and Streptomycin. Only the two species of Proteus were observed to be susceptible to Streptomycin. Streptomycin has always shown more activity against Gram positive bacteria than Gram negative bacteria. Among the Gram negative bacteria, only Proteus vulgaris was susceptible to all the antibiotics tested. Staphylococcus aureus was observed to be more susceptible to the antibiotics tested compared to Coagulase Negative Staphylococcus, the former was resistant to only three antibiotics, Ceftriaxone, Cefuroxime and Ampicillin-Cloxacillin (Figure 2). Both Gram positive bacteria isolated were susceptible to Streptomycin $(70-80 \%)$ as observed in figures 1 and 2 .

But in another study on acute otitis media in South Western Nigeria by Ako-Nai et al. (2002), Gram positive bacteria isolated showed a high percentage of resistance to Streptomycin in the range, $66.67-100.00 \%$. Their findings suggest that Ampicillin resistance may be transmitted simultaneously as resistance to Streptomycin, this trend was noticeable in this study, as high 
resistance to Ampicillin by E. coli and Pseudomonas aeruginosa was equally observed for Streptomycin by the same bacteria. In a similar study in Ghana, Pseudomonas aeruginosa was observed to be sensitive to Ciprofloxacin (93\%) and Gentamicin (73\%) (Appiah-Korang et al., 2014). This means Ciprofloxacin could possibly be used as an empirical ototopic agent in the management of ear discharge in the study area. Several studies recommended Ciprofloxacin as a safe and effective ototopic agent for the management of discharging ears in both adults and children (Legent et al., 1994; Mosges et al., 2011; Ahmad, 2013), this is because of its broad spectrum of activity towards a large variety of bacteria including, Pseudomonads, Escherichia, Staphylococci and Klebsiella spp. Sparfloxacin and Ofloxacin can also be used in the treatment of otitis media while considering the prescribing strategy for children. The fact that the three most prominent bacteria isolated (E. coli, Pseudomonas aeruginosa, and Staphylococcus aureus) are resistant to at least three antibiotics shows that there is multiple antibiotic resistance in the isolates thus, emphasizing the need for antibiotic susceptibility testing before the prescription of antibiotics. Also, these isolates could also serve as potential hosts of plasmids carrying antibiotic resistance genes.

\section{CONCLUSION}

The prevalence of otitis media observed in children attending a primary health facility in Samaru, Zaria was $54 \%$. Otitis media is prevalent amongst children between 6 months - 2 years of age $(24 \%)$. The infection was higher in males than in females. It is possible to postulate that the relatively high prevalence in children may be due to poor personal hygiene in addition to other environmental factors. Breast-feeding was also a factor affecting otitis media in that the infection was more prevalent in children not going through exclusive breast-feeding. From this study, the most prevalent bacteria isolated are Pseudomonas aeruginosa and Escherichia coli. Antibiotic susceptibility testing revealed that Ciprofloxacin, Sparfloxacin and Ofloxacin could be used for topical treatment of otitis media. Ciprofloxacin is an effective ototopic antibacterial agent for empirical treatment of ear infection. Prescription of antibiotics without laboratory guidance and sales of antibiotics without proper drug prescription may be some of the different factors that can contribute to high level drug resistant pattern.

\section{ACKNOWLEDGEMENTS}

We wish to express our gratitude to the staff of the Primary Health Care Centre, Samaru, Zaria, Kaduna State; for their kind assistance and cooperation in the collection of samples from the children.

\section{REFERENCES}

Ahmad, S. 2013. Antibiotics in chronic suppurative otitis media: A bacteriologic study. Egyptian Journal of Ear, Nose, Throat and Allied Sciences, 14(3):191-194.

Amusa, Y.B., Ijadunola, I.K.T. and Onayade, O.O. 2005. Epidemiology of otitis media in a local tropical African population. West African Journal of Medicine, 24: 227-230.

Appiah-Korang, L., Asare-Gyasi, S.,Yawon, A.E., Searyoh, K. 2014. Aetiological agents of ear discharge: A two year review in a teaching hospital in Ghana. Ghana Medical Journal. 48(2): 91-95.

Cheesbrough, M. (2006).District Laboratory Practice in Tropical Countries. Part II. 2nd Ed. New York: Cambridge University Press. Ch.7. pp.38-54, 64-70, 82-83,149,158.

CLSI (Clinical and Laboratory Standards Institute) (2014). Performance Standards for Antimicrobial Susceptibility; twentyfourth informational Supplements.34(1): 50-75.

Dewey, K.G., Heinig, M.J. and Nomsen-Rivers, L.A. 1995.Differences in morbidity between breast-fed and formula-fed infants. Journal of Pediatrics. 126(5): 690702.

Gulani, A. and Sachdev, H.S. 2014. Zinc Supplements for preventing otitis media. The Cochrane Database of Systemic Reviews. 6:39-66.

Ilechukwu, C. G., Ubesie, C.A., Ojinnaka, N.C., Emechebe, O.G. and Iloh, K.K. 2014. Otitis media in children. Open Journal of Pediatrics, 4: 47-53

Imane, E., Rachid, M., Maama, Y. and Mimoun, Z. 2014.Isolation and antibiotic susceptibility of bacteria from otitis 
media infections in children in Rabat Morocco. Journal of Biology, Agriculture and Healthcare, 4(28): 153-159.

Jido, B.A., Yahaya, A. and Yadock, L.H. 2014. Isolation and antimicrobial susceptibility pattern of Pseudomonas aeruginosa in cases of otitis media among patients attending Ahmadu Bello University Teaching Hospital, Zaria, Nigeria. European Journal of Biotechnology and Bioscience, .2(2), 18-23.

Khan, F., Muhammad, R., Khan, R.M., Rehman, F., Iqbal, J., Khan, M. and Gohar, Ullah. 2013. Efficacy of topical clotrimazole in the treatment of otomycosis. J.Ayub. Med. Coll. Abbottabad, 25(1-2): 78.

Legent, F., Bordure, P., Beauvillain, C., Berche, P. 1994. Controlled prospective study of oral ciprofloxacin versus amoxycillin/clavulanic acid in chronic suppurative otitis media in adults. Chemotherapy, 40 (Suppl 1): 16-23. doi: 10.1159/000239312.

Monasta, L., Ronfani, i., Marchetti, F., Montico, M., Vrecchi-Brunneti, L., Bavcar, A., Grasso, D., Barbiero, C. and Tamburlini, G. 2012. Burden of disease caused by otitis media: Systemic Review and Global Estimates. PLOS ONE, 7(4): 36226.

Moses, C. 2010. Microbiology of chronic otitis media at Queen Elizabeth Central Hospital, Blantyre, Malawi. Thesis submitted in partial fulfillment of the requirements for the award of the Degree of Masters of Medicine in ENT, Head and Neck Surgery at the University of Nairobi.

Mösges, R., Nematian-Samani, M., Eichel, A. 2011. Treatment of acute otitis externa with ciprofloxacin otic $0.2 \%$ antibiotic ear solution. Therapeutics and Clinical Risk
Management, 7:325-336.

Muluye, D., Wondimeneh, Y., Ferede, G., Moges, F. and Nega, T. 2013. Bacterial isolates and drug susceptibility patterns of ear discharge from patients with ear infection at Gondar University Hospital, Northwest Ethiopia. BioMed. Central, 13(10): 1-5.

Nwogwugwu, U.N., Dozie, N.I., Chinakwe, C.E., Nwachukwu, N.I. and Onyemekara, N.N. 2014. The Bacteriology of Discharging Ear (Otitis Media) Amongst Children in Owerri, Imo State, South East Nigeria. British Microbiology Research Journal, 4(7): 813-820.

Nwokoye, N.N., Egwari, L.O., Coker, A.O., Olubi, O.O., Ugoji, E.O and Nwachukwu, S.C.U. 2012. Predisposing and bacteriological features of otitis media. African Journal of Microbiology Research, 6(3): 520-525.

Ogbogu, I.P., Eghafona, O.N. and Ogbogu, I.M. 2013. Microbiology of Otitis Media Among Children Attending a Tertiary Hospital in Benin City, Nigeria. Journal of Pediatrics, 5(7): 280-284.

Price, L.B., Hungate, B.A., Koch, B.J., Davis, G.S., Liu, C.M. 2017 Colonizing opportunistic pathogens (COPs): The beasts in all of us. PLoS Pathog, 13(8): e1006369. https://doi.org/10.1371/journal.ppat.1 006369

Tikaram, A., Chew, Y.K., Zulkiflee, A.B., Chong, A.W. and Prepageran, N. 2012. Prevalence and Risk Factors Associated With Otitis Media with Effusion in Children Visiting Tertiary Care Centre in Malaysia. The International Medical Journal Malaysia, 11(1): 73. 